Sugeng Triyani ${ }^{1}$, Fatimah $^{2}$, Aisyah $^{3}$

Pengaruh Hypnosis Terhadap Tingkat Kecemasan Ibu Hamil Nullipara .....

\title{
PENGARUH HYPNOSIS TERHADAP TINGKAT KECEMASAN IBU HAMIL NULLIPARA TRIWULAN III DALAM PERSIAPAN MENGHADAPI PERSALINAN
}

\section{THE INFLUENCE OF HYPNOSIS AGAINST NULLIPAROUS WOMEN'S ANXIETY LEVEL IN THE THIRD QUARTER IN PREPARATION FOR CHILDBIRTH}

\author{
Sugeng Triyani ${ }^{1}$, Fatimah $^{2}$, Aisyah $^{3}$ \\ ${ }^{12,3}$ Jurusan Kebidanan Poltekkes Kemenkes Jakarta III, Jakarta, Indonesia
}

\section{Informasi Artikel}

Diterima: Oktober 2016

Disetujui: Oktober 2016

Kata kunci:

Kata kunci: Kecemasan, hypnobirting, persiapan persalinan, nullipara

\begin{abstract}
ABSTRAK
Kemampuan adaptasi ibu hamil terhadap persiapan persalinan sangat penting. Jika ibu tidak dapat beradaptasi maka selama proses persalinan biasanya ibu akan mengalami kecemasan dan akan memberikan respon melawan atau menghindar (fight or flight) yang dipicu oleh melimpahnya hormon katekolamin serta dipicu oleh adanya ketakutan dan bentuk distres lainnya. Penelitian ini menggunakan metode kuasi eksperimen dengan rancangan non randomized pretest potest equivalent group design, tanpa intervensi pada kelompok pembanding. Angket kecemasan HARS (Hamilton Ancienty Rating Scale) digunakan untuk mengukur tingkat kecemasan antara ibu hamil yang diberi terapi hypnosis dengan ibu hamil yang tidak diberi terapi hypnosis. Hasil penelitian menunjukkan ada perbedaan yang bermakna antara rata-rata tingkat kecemasan pada sampel kasus dengan tingkat kecemasan dengan sampel kontrol (Standar Deviasi sebesar 6,004). Terdapat pengaruh yang bermakna pada kelompok yang menggunakan terapi hypnosis dengan rata-rata penurunan kecemasan sebesar 21,550 poin dengan nilai $\mathrm{p}$ value $<0,001$. Oleh karena itu, hipnosis berpengaruh dalam menurunkan tingkat kecemasan ibu nullipara di triwulan III
\end{abstract}

\begin{abstract}
Adaptability of pregnant women toward labor preparation is very important. If the mother cannot adapt during the process of labor, usually she will experience anxiety and will give a response of fight or flight triggered by the abundance of Catecholamines hormones and by the presence of fear and other forms of distress. This research used a quasi experiment method with non randomized pretest potest equivalent group design, without intervention on the comparison group. The quetionnaire of Hamilton Ancienty Rating Scale was used to measure the level of anxiety among pregnant women given hypnosis therapy with pregnant women not given the hypnosis therapy. The results showed that there was a significant difference in the mean level of anxiety between cases and controls (SD of 6,004). There was a significant influence on the group that used hypnosis therapy with a mean decrease in anxiety by 21.550 poin with a $p$ value of $<0.001$. Therefore, hypnosis is effective in reducing anxiety among nulliparous women in the third quarter of pregnancy.
\end{abstract}




\section{PENDAHULUAN}

Ibu yang sedang hamil mudah mengalami kecemasan, kemurungan, kegusaran dan mudah menangis. Kecemasan ibu hamil dapat mempengaruhi pertumbuhan otak janinnya. Disadari atau tidak, emosi apapun yang dirasakan oleh seorang ibu akan dirasakan sang janin. Banyak penelitian membuktikan bahwa emosi negatif yang berkepanjangan pada ibu hamil akan berpengaruh pada mentalitas dan karakter anak dikehidupannya kelak.

Perubahan psikologis pada masa kehamilan yang tidak dapat ditangani oleh ibu yang sedang hamil umumnya akan menyebabkan terjadinya stres. Menurut Handayani dari bagian Psikologis Klinis Anak Fakultas Psikologi Universitas Indonesia, stres pada ibu hamil dapat terjadi pada tiga tahapan, yaitu tahapan pertama pada trimester awal, tahap kedua pada trimester dua dan tahap ketiga pada trimester akhir (Apriani, 2005).

Pada kehamilan trimester III, ibu hamil selalu dihinggapi perasaan takut yang lebih dibandingkan sebelumnya. Hal ini dikarenakan ketakutan ibu dalam menghadapi persalinannya. Apabila keadaan tersebut tidak dapat diatasi oleh ibu, maka pada saat menjelang dan selama proses persalinan, biasanya ibu akan mengalami kecemasan dan akan memberikan respons melawan atau menghindar (fight or flight) yang dipicu oleh melimpahnya hormon katekolamin serta dipicu oleh adanya ketakutan dan bentuk distres lainnya (Simkin dan Ancheta, 2005 dalam Aprillia, 2010). Informasi tentang pengalaman persalinan yang menakutkan dan tidak utuh juga menambah kecemasan pada ibu hamil (Andriana, 2007).

Faktor-faktor yang mempengaruhi kecemasan pada ibu hamil diantaranya adalah kurangnya informasi mengenai penyakit, dukungan keluarga, kecukupan keuangan (Lexshimi, dkk; 2007), stres dari lingkungan (Cury \& Menezes, 2007), frekuensi mual dan muntah

\footnotetext{
Alamat E-mail: tulis alamat email disini
}

yang tinggi (faktor kesehatan fisik ibu hamil) (Swallow, dkk.,2004), sikap terhadap kehamilan (Gurung, Schetter, Collins, \& Hobel,2005), kemampuan penguasaan kehamilan (Gurung, dkk., 2005), proses penyesuaian diri terhadap kehamilan (Bibring, dalam Stotland \& Stewart, 2001) baik secara fisik (Andriana, 2007) maupun psikososial (Gross dan Helen, 2007), serta informasi tentang pengalaman persalinan yang menakutkan (Andiana, 2007). Meskipun wajar terjadi pada ibu hamil, jika berlebihan kecemasan dapat membawa dampak buruk baik bagi ibu hamil maupun bagi perkembangan janin, misalnya menyebabkan rendahnya skor APGAR bayi ketika lahir (Berle, dkk., 2005), meningkatnya kemungkinan ibu mengalami depresi postpartum (Skouteris, dkk., 2008), dan dapat mempengaruhi kesehatan fisik dan mental ibu dan janin (Ferti, dkk., 2009) misalnya melalui turunnya fungsi plasenta ibu (Glover, Bergman, Sarkar, \& O'Connor, 2008) yang kemudian dapat mempengaruhi kesehatan fisik dan mental janin, serta terhambatnya pertumbuhan organ dan fungsi fisiologis serta perkembangan psikologis bayi (Monk, 2001).

Salah satu intervensi yang telah terbukti efektif untuk mengurangi kecemasan dan telah sering digunakan adalah metode hypnobirthing yang salah satunya terdapat teknik relaksasi. Beech dkk (dalam Subandi, 2002) menyebutkan bahwa ketegangan merupakan kontraksi serabut otot skeletal, sedangkan relaksasi merupakan perpanjangan serabut otot tersebut. Pada waktu orang mengalami ketegangan dan kecemasan yang bekerja adalah sistem syaraf simpatetis, sedangkan pada waktu rileks yang bekerja adalah sistem syaraf parasimpatetis. Relaksasi berusaha mengaktifkan kerja syaraf parasimpatetis (Bellack $\&$ Hersen, serta Prawitasari dalam Subandi, 2002). Keadaan rileks menurunkan aktivitas amygdala, mengendurkan otot, dan melatih individu mengaktifkan kerja sistem syaraf parasimpatetis sebagai counter aktivitas sistem syaraf simpatetis (Kalat, 2007). Relaksasi untuk mengatasi kecemasan ibu hamil juga sudah banyak dibuktikan keberhasilannya (Chambers, 2007; Teixeira, dkk., 2005; Saisto, Toivanen, Aro, \& 
Halmesmaki., 2006). Beberapa penelitian di Indonesia juga telah membuktikan efektivitas teknik relaksasi dalam metode hypnobirthing untuk menurunkan tingkat kecemasan ibu hamil (Reni Ilmiasih, 2009; Siti Malicha, 2011; Yuyun Puspitasari, 2011).

Hypnobirthing banyak memberikan manfaat karena melatih ibu hamil untuk selalu rileks, bersikap tenang, dan menstabilkan emosi. Hypnobirthing bertujuan agar ibu dapat melahirkan dengan nyaman dan menghilangkan rasa sakit melahirkan tanpa bantuan obat bius apapun (Andriana, 2007). Metode ini juga lebih menekankan melahirkan dengan cara positif, lembut, aman dan bagaimana mencapainya dengan mudah.

Menurut Andriana (2007), pada metode hypnobirthing ibu akan dilatih untuk menanamkan pikiran positif dan melakukan hipnosis diri. Para ahli kejiwaan berpendapat bahwa relaksasi yang mendalam, pemusatan perhatian (fokus), dan hipnosis berguna untuk lebih banyak mengistirahatkan alam sadar dan memasukkan pemahaman kepada alam bawah sadar sehingga tindakan akan lebih banyak dipengaruhi oleh alam bawah sadar dibandingkan dengan alam sadar.

Dalam Journal of Counselling and Clinical Psychology (1990), sebuah penelitian mengenai hypnobirthing dilakukan pada dua kelompok ibu hamil. Kelompok pertama diberi latihan pernafasan dan relaksasi, kelompok kedua diberi metode hypnobirthing dan hasilnya kelompok kedua lebih bisa mengatasi nyeri, dan terlihat tenang ketika persalinan dan bayi yang dilahirkan memiliki Apgar score tinggi dan juga mengurangi terjadinya depresi pada masa postpartum (http://www.healthwisemag.com)

Belakangan ini di Indonesia telah banyak sarana pelayanan kesehatan yang memasukkan metode hypnobirthing ke dalam pelayanan asuhan kehamilan dan persalinan tetapi beberapa sarana kesehatan belum menjadikan program ini ke dalam pelayanannya. Fenomena yang peneliti temui di beberapa lahan praktik pelayanan kesehatan yang belum menggunakan metode hypnobirthing adalah tidak sedikit ibu bersalin yang berteriak-teriak dan merasa kebingungan dalam menghadapi proses persalinan yang sedang dialaminya, dan umumnya para petugas kesehatan lebih menganggap hal tersebut sebagai hal yang lumrah dirasakan oleh setiap ibu bersalin.

Bidan sebagai tenaga pelayanan kesehatan, khususnya dalam bidang kesehatan ibu dan anak, juga harus menjadi pelaku inovasi dengan menggunakan metode-metode terbaru untuk melakukan asuhan kebidanan, salah satunya adalah metode hypnobirthing. Metode hypnobirthing dapat membantu membuat rileks otot-otot sehingga ibu terhindar dari kecemasan dan dapat membantu ibu lebih tenang dalam menghadapi persalinan. Selain itu, hypnobirthing mampu melancarkan air susu ibu (ASI) bagi ibu setelah melahirkan, menjaga agar baby blues tidak terjadi, menjadikan bayi yang sehat secara fisik dan psikologi, mengontrol emosi ibu agar terhindar dari stres, serta menjaga diri ibu dari ketakutan dalam kehidupan sehari-hari agar terhindar dari depresi. Semua itu didasari dengan pengendalian fikiran negatif yang dapat membuat tubuh menjadi sakit tetapi lebih mengembangkan fikiran yang positif (Pro-Vclinic, 2008). Penelitian yang dilakukan oleh Ilmiasih (2010) menunjukkan bahwa tingkat kecemasan ibu hamil sesudah melaksanakan latihan relaksasi hypnobirthing adalah 56\% tidak cemas dan $38 \%$ tingkat kecemasan ringan.

Puskesmas Kecamatan Cengkareng telah menerapkan metode hypnobirthing kepada ibu hamil dan bersalin sejak tahun 2009. Berdasarkan pengamatan peneliti kepada 5 orang ibu yang sedang dalam proses persalinannya dan mendapat latihan hypnobirthing, para ibu tersebut tampak tenang dan tidak cemas serta dapat mengendalikan diri terhadap rasa nyeri persalinan. Namun, bagi 10 ibu hamil trimester III yang berkunjung untuk ANC pada periode Januari 2012 dan tidak mendapatkan pelatihan hypnobirthing, $75 \%$ mengalami kecemasan dan menyatakan rasa takut dengan kehamilan dan proses persalinan yang akan berlangsung pada ibu hamil nullipara. Penelitian ini bertujuan untuk mengetahui pengaruh metode relaksasi hypnobirthing terhadap tingkat kecemasan ibu hamil nullipara triwulan 3 pada masa persiapan menghadapi persalinan di Puskesmas Kecamatan Cengkareng Jakarta Barat Periode Juni - Oktober Tahun 2012. 


\section{METODE PENELITIAN}

Penelitian ini adalah penelitian quasi eksperiment dengan desain penelitian the untreated control group design with dependent pretest and posttest samples (Shadish, dkk., 2002). Rancangan penelitian ini bertujuan untuk menyelidiki ada tidaknya pengaruh sebab akibat serta seberapa besar pengaruhnya metode hypnosis terhadap tingkat kecemasan ibu hamil menghadapi persalinan. Jenis data yang digunakan pada penelitian ini adalah data primer. Alat yang digunakan dalam penelitian ini antara lain adalah informed consent, quesioner tingkat kecemasan HARS (Hamilton Ancienty Rating Scale) yang sudah diukur validitas dan reliabilitasnya, modul untuk fasilitator, booklet materi pelatihan untuk peserta, lembar kerja peserta, CD panduan latihan, lembar observasi pelatihan, dan lembar evaluasi pelatihan. Jumlah sampel adalah sebanyak 20 orang pada kelompok kasus dan 20 orang pada kelompok control.

Tehnik pengumpulan data dengan cara membagikan kuesioner tingkat kecemasan sebelum dilaksanakan latihan dan pendampingan teknik hypnobirthing. Pendampingan dilaksanakan sebanyak 4 kali kunjungan dengan selang waktu masing-masing kunjungan adalah 2 minggu dan peserta diberikan kartu frekuensi latihan sendiri di rumah sebanyak minimal 3 kali dalam satu minggu. Pada pendampingan yang keempat dilakukan evaluasi dengan membagikan kuesioner tingkat kecemasan. Alat yang digunakan dalam penelitian adalah kaset dan $C D$ musik atau lagu kesayangan yang memiliki nada atau irama berulang-ulang, tenang, serta lembut untuk menimbulkan respons tubuh terbaik.

Alur pelatihan mengacu pada alur pelatihan relaksasi ibu hamil yang disusun oleh Marie $\mathrm{F}$ Mongan (2002), Yesie Aprillia (2010), dan Lanny Kuswandi (2011). Sesi-sesi pelatihan dilaksanakan dalam 4 kali pertemuan. Dalam dua minggu dilaksanakan satu pertemuan yang masing-masing berdurasi $2-2,5$ jam. Sesi-sesi utamanya terdiri atas 3 sesi, yaitu materi pengantar (materi kecemasan kehamilan dan cara mengatasinya, materi perjalanan kehamilan hingga persalinan, materi pengenalan teknik relaksasi dengan hypnobirthing) yang disajikan melalui teknik ceramah dan audiovisual, sesi praktik relaksasi dengan hypnobirthing (konsentrasi fikiran, relaksasi pernafasan, komunikasi dengan janin) yang diberikan melalui teknik simulasi, sesi diskusi pengalaman kehamilan dan pengalaman praktik di rumah yang diberikan melalui teknik diskusi, serta penugasan praktik relaksasi dengan hypnobirthing di rumah 3 kali dalam satu minggu.

Tekhnik hypnosis yang digunakan adalah:

a. Posisi relaksasi (the mongan methods)

b. Konsentrasi pikiran (tekhnik pendulum, teknik bola energy, menggerakkan lengan

c. Relaksasi pernafasan

d. Relaksasi visualisasi

e. Komunikasi dengan janin

\section{HASIL DAN PEMBAHASAN}

Salah satu syarat analisis uji $\mathrm{T}$ adalah data terdistribusi normal, dan hal ini dapat dilihat dari uji normalitas (tests of normality) dan hasil yang diperoleh adalah sebagai berikut :

Tabel 1: Tests of Normality

\begin{tabular}{|l|l|l|l|l|l|l|}
\hline & \multicolumn{3}{|l|}{ Kolmogorov-Smirnov } & \multicolumn{3}{l|}{ Shapiro-Wilk } \\
\cline { 2 - 7 } & Statistic & Df & Sig. & $\begin{array}{l}\text { Statis } \\
\text { tic }\end{array}$ & Df & Sig. \\
\hline $\begin{array}{l}\text { Tingkat } \\
\text { kecemasan } \\
\text { sebelum } \\
\text { hypnobirthing }\end{array}$ & .192 & 20 & .052 & .944 & 20 & .288 \\
$\begin{array}{l}\text { Tingkat } \\
\text { kecemasan } \\
\text { sesudah } \\
\text { hypnobirthing }\end{array}$ & .209 & 20 & .022 & .913 & 20 & .072 \\
\hline
\end{tabular}

Untuk melihat normalitas dari tabel nomor 1, digunakan Shapiro Wilk karena jumlah sampel kurang dari atau sama dengan 50 sampel. Data dikatakan terdistribusi normal jika nilai 
Pengaruh Hypnosis Terhadap Tingkat Kecemasan Ibu Hamil Nullipara .....

signifikansinya lebih dari 0,05. Dari tabel diperoleh hasil signifikansi 0,288 dan 0,072, yang berarti bahwa data terdistribusi normal maka analisis dengan menggunakan uji $\mathrm{T}$ dapat dilanjutkan.
Tabel 2 Rata-rata Tingkat Kecemasan Sebelum dan Sesudah Hypnobirthing

\begin{tabular}{|l|l|l|l|l|}
\hline Variabel & Mean & SD & SE mean & N \\
\hline Pra & 24,10 & 9,095 & 2,034 & 20 \\
\hline Post & 2,55 & 1,986 & 0,444 & 20 \\
\hline
\end{tabular}

Dari tabel 2 dapat diketahui bahwa dari 20 sampel yang diamati terlihat bahwa rata-rata tingkat kecemasan sebelum hypnobirthing adalah 24,10 dan rata-rata tingkat kecemasan sesudah hypnobirting adalah 2,55.

Table 3 : Uji T Berpasangan Tingkat Kecemasan Sebelum dan Sesudah Hypnobirthing

Paired Samples Test

\begin{tabular}{|c|c|c|c|c|c|c|c|c|c|}
\hline & & \multicolumn{5}{|c|}{ Paired Differences } & \multirow[t]{3}{*}{$\mathbf{T}$} & \multirow[t]{3}{*}{ df } & \multirow{3}{*}{$\begin{array}{l}\text { Sig. (2- } \\
\text { tailed) }\end{array}$} \\
\hline & & \multirow[t]{2}{*}{ Mean } & \multirow[t]{2}{*}{ Std. Deviation } & \multirow[t]{2}{*}{$\begin{array}{l}\text { Std. } \\
\text { Error } \\
\text { Mean }\end{array}$} & \multicolumn{2}{|c|}{$\begin{array}{l}\text { 95\% Confidence } \\
\text { Interval of the } \\
\text { Difference } \\
\end{array}$} & & & \\
\hline & & & & & Lower & Upper & & & \\
\hline Pair 1 & 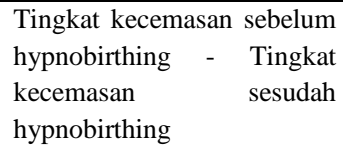 & 21.550 & 8.793 & 1.966 & 17.435 & 25.665 & 10.961 & 19 & .000 \\
\hline
\end{tabular}

Dari uji-t berpasangan pada tabel 3 dapat diketahui bahwa rata-rata perbedaaan antara tingkat kecemasan sebelum hypnobirthing dengan tingkat kecemasan sesudah hypnobirthing adalah sebesar 21,550. Artinya, dalam perhitungan ini terdapat penurunan tingkat kecemasan sesudah intervensi dengan rata-rata penurunan 21,550 poin. Hasil uji statistik menunjukkan nilai p 0,000. Hal ini berarti terdapat perbedaan yang bermakna antara rata-rata tingkat kecemasan sebelum dan sesudah intervensi hypnotbirthing.
Tabel 4: Distribusi Rata-rata Tingkat Kecemasan Sebelum dan Sesudah Hypnobirthing

\begin{tabular}{|l|l|l|l|l|}
\hline Variabel & Mean & SD & SE mean & N \\
\hline Kasus & 2,55 & 1,986 & 0,444 & 20 \\
\hline Kontrol & 9,60 & 6,004 & 1,342 & 20 \\
\hline
\end{tabular}

Dari tabel 4 dapat diketahui bahwa dari 40 sampel yang diamati terlihat bahwa rata-rata tingkat kecemasan pada sampel kasus adalah 2,55 dan rata-rata tingkat kecemasan pada sampel control adalah 9,60. 
Tabel 5: Uji T Tidak Berpasangan Tingkat Kecemasan pada Sampel Kasus dan Kontrol

Independent Samples Test

\begin{tabular}{|c|c|c|c|c|c|c|c|c|c|c|}
\hline & \multicolumn{2}{|c|}{$\begin{array}{c}\text { Levene's Test } \\
\text { for Equality of } \\
\text { Variances } \\
\end{array}$} & \multicolumn{7}{|c|}{ t-test for Equality of Means } \\
\hline & & \multirow[t]{2}{*}{$\mathbf{F}$} & \multirow[t]{2}{*}{ Sig. } & \multirow[t]{2}{*}{$\mathbf{T}$} & \multirow[t]{2}{*}{ df } & \multirow[t]{2}{*}{$\begin{array}{l}\text { Sig. (2- } \\
\text { tailed) }\end{array}$} & \multirow[t]{2}{*}{$\begin{array}{c}\text { Mean } \\
\text { Differenc } \\
\text { e }\end{array}$} & \multirow[t]{2}{*}{$\begin{array}{l}\text { Std. Error } \\
\text { Difference }\end{array}$} & \multicolumn{2}{|c|}{$\begin{array}{c}\text { 95\% Confidence } \\
\text { Interval of the } \\
\text { Difference }\end{array}$} \\
\hline & & & & & & & & & Lower & Upper \\
\hline \multirow{2}{*}{ Tktcemas } & $\begin{array}{l}\text { Equal variances } \\
\text { assumed }\end{array}$ & \multirow[t]{2}{*}{22.812} & \multirow[t]{2}{*}{.000} & - & & .000 & -7.050 & 1.414 & -9.912 & -4.188 \\
\hline & $\begin{array}{l}\text { Equal variances } \\
\text { not assumed }\end{array}$ & & & - & $\begin{array}{l}23.11 \\
0\end{array}$ & .000 & -7.050 & 1.414 & -9.974 & -4.126 \\
\hline
\end{tabular}

Dari hasil uji-t pada tabel 9 tidak berpasangan tersebut terlihat bahwa rata-rata perbedaaan antara tingkat kecemasan pada sampel "kasus" dengan tingkat kecemasan adalah 2,55 dengan standar deviasi 1,986 , sedangkan rata-rata tingkat kecemasan pada sampel "kontrol" adalah sebesar 9,60 dengan standar deviasi 6,004. Hasil uji statistik menunjukkan nilai $\mathrm{p}$ value 0,000 , yang berarti bahwa terdapat perbedaan yang bermakna antara rata-rata tingkat kecemasan pada sampel "kasus" dan "kontrol"

Hipotesis dalam penelitian ini terbukti, yaitu pelatihan relaksasi dengan metode hypnobirthing secara bermakna dapat mengurangi kecemasan subjek dalam menghadapi kehamilan nullipara dalam persiapan menghadapi persalinan. Hal ini terlihat dari hasil Uji T-Paired Corelation Sampel Test dengan perbedaan yang bermakna antara ratarata tingkat kecemasan pada sampel kasus dengan tingkat kecemasan 2,55 dan Standar Deviasi 1,986 dan sampel kontrol sebesar 9,60 dan Standar Deviasi sebesar 6,004. Dalam penelitian ini terdapat pengaruh yang bermakna antara intervensi hypnobirthing dengan penurunan tingkat kecemasan, dengan perbedaan rata-rata tingkat kecemasan sebelum dan sesudah intervensi hypnotbirthing. Hasil penelitian yang bermakna ini mendukung beberapa penelitian sebelumnya yang menyatakan bahwa hypnobirthing dapat mengatasi kecemasan ibu hamil (Ilmiasih, 2009; Malicha, 2011). Penelitian ini dapat membuktikan bahwa metode hypnobirthing dapat membantu mengurangi kecemasan pada ibu hamil nullipara yang rentan karena belum berpengalaman.

Adanya fikiran-fikiran seperti melahirkan yang akan selalu diikuti dengan nyeri akan menyebabkan peningkatan kerja sistem syaraf simpatetik. Dalam situasi ini, sistem endokrin, yang terdiri dari kelenjar-kelenjar, seperti adrenal, tiroid, dan pituitary (pusat pengendalian kelenjar), melepaskan pengeluaran hormon masing-masing ke aliran darah dalam rangka mempersiapkan badan pada situasi darurat. Akibatnya, system syaraf otonom mengaktifkan kelenjar adrenal yang mempengaruhi sistem pada hormon epinefrin. Peningkatan hormon adrenalin dan noradrenalin atau epinefrin dan norepinefrin menimbulkan disregulasi biokimia tubuh, sehingga muncul ketegangan fisik pada diri ibu hamil. Dampak dari proses fisiologis ini dapat timbul pada perilaku sehari-hari. Ibu hamil menjadi mudah marah atau tersinggung, gelisah, tidak mampu memusatkan perhatian, ragu-ragu, bahkan kemungkinan ingin lari dari kenyataan hidup (Dariyo, 1997 dalam Aprillia.2010).

Kondisi ini dapat menyebabkan kecemasan dan ketegangan lebih lanjut sehingga membentuk suatu siklus umpan balik yang dapat meningkatkan 
intensitas emosional secara keseluruhan. Adanya pengaruh latihan relaksasi terhadap tingkat kecemasan dapat dijelaskan dengan teori dan cara kerja hipnobirthing.

Metode hypnobirthing membantu memusatkan perhatian berdasarkan pada keyakinan bahwa perempuan dapat mengalami persalinan melalui insting untuk melahirkan secara alami dengan tenang, nyaman, percaya diri. Latihan ini mengajarkan ibu hamil menjalankan teknik relaksasi yang alami, sehingga tubuh dapat bekerja dengan seluruh syaraf secara harmonis dan dengan kerjasama penuh. Rangkaian teknik relaksasi mulai dari relaksasi otot, relaksasi pernafasan, relaksasi pikiran dan penanaman kalimat positif, komunikasi dengan janin yang dilakukan secara teratur dan konsentrasi akan menyebabkan kondisi rileks pada tubuh sehingga tubuh memberikan respons untuk mengeluarkan hormon endorfin yang membuat ibu menjadi rileks dan menurunkan rasa nyeri terutama ketika otak mencapai gelombang alfa atau saat istirahat. Pada kondisi ini, tubuh mengeluarkan hormon serotonin dan endorfin sehingga manusia dalam kondisi rileks tanpa ketegangan dan kecemasan (workbook pelatihan basic hypnosis and hypnobirthing, 2010). Pemberian latihan relaksasi hypnobirthing berpengaruh terhadap tingkat kecemasan ibu hamil. Penurunan tingkat kecemasan ini dikarenakan teknik relaksasi hypnobirthing ini mempunyai cara kerja dengan membawa kerja otak pada gelombang alfa, yaitu gelombang yang memiliki frekuensi14-30 HZ. Pada kondisi ini, otak dalam keadaan relaks, santai, antara sadar dan tidak dan nyaris tertidur, saat tubuh mulai mengeluarkan hormon serotonin dan endorfin sehingga ibu hamil menjadi rileks dan menghilangkan kecemasan atau paling tidak kecemasan menurun (Evarini, 2007).

\section{KESIMPULAN}

Skor kecemasan pretest dan posttest menunjukkan perbedaan selisih serta perbedaaan yang bermakna terjadi antara tingkat kecemasan pada kelompok kasus dengan kelompok kontrol. Oleh karena itu, pelatihan dengan metode hypnobirthing dapat menurunkan kecemasan ibu hamil nullipara dalam menghadapi persalinan.

\section{DAFTAR PUSTAKA}

Andriana, Evarini. (2007). Melahirkan Tanpa Rasa Sakit (dengan Metode Relaksasi hypnoBirthing). Edisi Revisi. Jakarta: Penerbit PT. Bhuana Ilmu Populer.

Annatagia, L. (2010). Relaksasi Bumil Sehat untuk Menurunkan Kecemasan Ibu Hamil Risiko Tinggi. Tesis. Yogyakarta: Fakultas PsikologiUniversitas Gadjah Mada.

Adewuya, A. O., Ola, B. A., Aloba, O. O., \& Mapayi, B. M. (2006). Anxiety Disorders Among Nigerian Women In Late Pregnancy: A Controlled Study. Archives of Women's Mental Health.

Aprillia S.Si.T, Mkes. 2010. Hipnostetri, Rileks, Nyaman, dan Aman Saat Hamil \& melahirkan, Jakarta : gagas Media Andriana, Hypnobirthing. Jakarta:Grasindo. 2008

\section{Barbara. C, Long.( 1999). Psikiatri. Jakarta EGC}

Barlow, D. H. 2002. Anxiety and Its Disorders: The Nature and Treatment of Anxiety and Panic, Second Edition. New York: The Guilford Press.

Berle, J. O., Mykletun, A., Daltveit, A. K., Rasmussen, S., Holsten, F., \& Dahl,

A. A. (2005). Neonatal Outcomes In Offspring Of Women With Anxiety And Depression During Pregnancy. Archives of Women's Mental Health.

Cury, A. F. \& Menezes, P. R. (2007). Prevalence of anxiety and depression during pregnancy in a private setting sample. Archives Womens Mental Health.

Chambers, A. S. (2007). Relaxation During Pregnancy to Reduce Stress And Anxiety and Their Associated Complications.. Arizona: Department Of Psychology, The University Of Arizona.

Davis, M., Eshelman, E. R., \& McKay, M. (1995). Panduan Relaksasi dan Reduksi Stres (Terjemahan), Edisi III. Jakarta: Penerbit Buku Kedokteran EGC.

Davison, G. C., Neale, J. M., \& Kring, A. M. (2004). Psikologi Abnormal Edisi Ke-9 (Terjemahan). Jakarta: PT. Raja Grafindo Persada.

F.Gary Cunningham, et al. 2005.Williams Obstetrics 22nd Edition. New York:McGraw-Hill Companies.

Gurung, R. A. R., Schetter, C. D., Collins, N., Rini, C., \& Hobel, C. J. (2005). Psychosocial Predictors Of 
Prenatal Anxiety. Journal of Social and Clinical Psychology.

Glover, V., Bergman, K., Sarkar, P., \& O’Connor, T. G. (2008). Association Between Maternal and Amniotic Fluid Cortisol is Moderated by Maternal Anxiety. Journal of Psychoneuroendocrinology.

Gross, H. \& Helen, P. (2007). Researching Pregnancy: Psychological Perspective. New York: Routledge.

Halgin, R. P. \& Whitbourne, S. K. (2005). Abnormal Psychology: Clinical Perspective on Psychological Disorders. Fourth Edition. New York: McGraw Hill Companies, Inc. Hamilton M. 1959. The assessment of anxiety stress by rating. Br J Med Psycol.

Kalat, J. W. (2007). Biological Psychology. California: Thomson Learning, Inc.

Kuswandy, Lanny.(2003 ). Terapi Hynobirthing: melahirkan tanpa rasa sakitpersalinan . http:// group. Yahoo.com/ group/ kelg-islami/ massage/ 15921. Diakses tanggal 10 April 2009.

Lawrence, S. M., \& McNeil, D. W. (2002). Relaxation Training. Ensyclopedia of Psychotherapy. American Psychiatric Association.

Lexshimi, R. R. G., Ho, S. E., Hamidah, H., Rohani, M., \& Syed, Z. S. Z. (2007). A Study On Anxiety And Depression Level Among High Risk Inpatient Pregnant Women In An Obstetric Ward. Journal of Medical and Health, 2.

Lovarini, M. (2007). At Least 9 H Of Supervised Relaxation Training May Reduce State Anxiety And Improve Heart Rate Variability, Prognosis And Return To Work For People With Ischaemic Heart Disease. Journal compilation Australian Association of Occupational Therapists.

Laazulva, I. (2003). Promosi Kesehatan Melalui Pelatihan Relaksasi Otot Sebagai Upaya Menurunkan Kecemasan dan Keluhan Fisik pada Remaja yang Mengalami Kehamilan Tidak Dikehendaki (KTD) di Yogyakarta. Tesis. Yogyakarta: Program Pascasarjana Universitas Gadjah Mada.

Marie F Mongan, M. Ed., M.Hy.2007. Hypnobirthing The Mongan Methode, Metode Melahirkan Secara Aman, Mudah, dan Nyaman, Alih Bahasa : Brahm Udumbara, Penerbit PT Bhuana Ilmu Populer

Mead, G E., Greig, C. A., Cunningham, I., Lewis, S. J., Dinan, S., Saunders, D.H., Fitzsimons, C., \& Young, A. (2007). Stroke: A Randomized Trial of Exercise or Relaxation. Journal Compilation, The American Geriatrics Society.

Mochtar, Rustam, dkk. (2006) Sinopsis obstetri, obstetric operatif dan social: jilid II. Jakarta: EGC.
Monat \& Lazzarus R )(1977). Kecemasan and coping and anthrology. Colombia University Press. New York.

Moebito. (2000). Srtess dan Manajemennya. Makalah disampaikan pada PelatihanKepemimpinan dan Manajemen keperawatan bagi Kepala Ruangan (Angk. II) di Bapelkes Munajati Tanggal 6 s/d 12 Agustus. Lawang.

Myles, MF. 1975. Textbook For Midwives with Modern Concepts of Obstetric nd Neonatal Care. London: Churshill Livingstone

Nadhiroh, Zumrotin. (2004). Pengaruh pemberian pendidikan Kesehatan Terhadap Tingkat Kecemasan Ibu Primigravida dalam Menghadapi Rasa Nyeri Persalinan diPuskesmas Dinoyo Malang. Karya Tulis Ilmiah Program Diploma III Keperawatan Universitas Muhammadiyah Malang.

Nasuhah, R. (2005). Hubungan Latihan Relaksasi Senam Hamil Terhadap Tingkat Kecemasan pada Ibu Hamil. Skripsi. Malang: Universitas Muhamadiyah Malang.

\section{Nenti Mardyaningsih , (2012) Keefektifan Hypnobirthing untuk Mengurangi Kecemasan IbuHamil. Under Graduates thesis, Universitas Negeri Semarang.}

Ningrum, Y. W. (2009). Pelatihan Relaksasi Easybirthing untuk Menurunkan Kecemasan Persalinan pada Ibu Hamil Pertama Trimester III. Tesis. Yogyakarta: Fakultas Psikologi Universitas Gadjah Mada.

Nolan, M. 2003. Kehamilan dan Melahirkan (terjemahan). Jakarta: Arcan

Nursalam. 2003. Pendekatan Praktik Metodelogi Riset Keperawatan. Jakarta.Infomedika.-

Philip Sloane PD, Benedict S.( 2001). Petunjuk lengkap kehamilan. Jakarta: Penerbit Mitra Utama.

Prawitasari, J. E. dalam Subandi, M. A. (ed). (2002). Psikoterapi: Pendekatan konvensional dan Kontemporer. Yogyakarta: Pustaka Pelajar dan Unit Publikasi Fakultas Psikologi UGM.

Rathus, S. A., \& Nevid, J. S. (1991). Abnormal Psychology. New Jersey: Prentice

Hall.

Rout, U. R., \& Rout, J. K. (2002). Stress Management For Primary Health Care Proffessionals. New York: Kluwer Academic Publishers. 
Sugeng Triyani ${ }^{1}$, Fatimah $^{2}$, Aisyah $^{3}$

Pengaruh Hypnosis Terhadap Tingkat Kecemasan Ibu Hamil Nullipara .....

Ray. 2010. Kematian Ibu di Indonesia Tertinggi seAsia Tenggara. http://www.satudunia.net/content/kematian-ibu-diindonesia-tertinggise- asia-tenggara

Shadish, W. R., Cook, T. D., \& Campbell, D. T. (2002). Experimental and Quasi- Experimentation Designs For Generalized Causal Inference. Boston: Hoghton Mifflin Company.

Saisto, T., Toivanen, R., Aro, K. S., \& Halmesmaki, E. (2006). Therapeutic Group Psychoeducation And Relaxation In Treating Fear Of Childbirth. Acta Obstetricia et Gynecologica.

Sarafino, E. P. (1998). Health Psychology. Third Edition. Danver: John Willey and Sons

Sari, W. S. (2010). Purelax (Pregnancy Auto-Induced Relaxation) untuk Menurunkan Tingkat Stres Kehamilan Pada Ibu Hamil Primipara Trimester III. Tesis. Yogyakarta: Fakultas Psikologi Universitas Gadjah Mada.

Schafer, W. (2000). Stress Management for Wellness. Belmont: Thomson Learning Inc.

Shadish, W. R., Cook, T. D., \& Campbell, D. T. (2002). Experimental and Quasi- Experimentation Designs For Generalized Causal Inference. Boston: Hoghton Mifflin Company.

Skouteris, H., Wertheim, E. H., Rallis, S., Milgrom, J., \& Paxton, S. J. (2008).Depression and Anxiety Through Pregnancy and The Early Postpartum: An Examination of Prospective Relationships. Journal of Affective Disorders.

Stotland, N. L., \& Stewart, D. E. (2001). Psychological Aspects Of Women's Health Care (The Interface Between Psychiatry And Obstetrics And Gynecology), Second Edition. Washington, Dc: American Psychiatric Press, Inc.

Stuart dan Sudden.(1995 ) .Buku saku keperaawatan jiwa (edisi 3)". Terjemahan oleh Achir Yani S Hamid, 1998, Jakarta: EGC.

Swallow, B. L., Lindow, S. W., Masson, E. A., \& Hay, D. M. (2004). Psychological Health In Early Pregnancy: Relationship With Nausea And Vomiting. Journal of Obstetrics and Gynaecology.

Teixeira, J., Martin, D., Prendiville, O., \& Glover, V. (2005). The Effects Of Acute Relaxation On Indices Of Anxiety During Pregnancy. Journal of Psychosomatic Obstetrics \& Gynecology.

Wulandari, P. Y. (2003). Efektivitas Senam Hamil Sebagai Pelayanan Prenatal dalam Menurunkan Kecemasan Menghadapi Persalinan Pertama. Tesis.
Yogyakarta: Fakultas Psikologi Universitas Gadjah Mada.

Wulandari, P. Y. (2006). Efektivitas Senam Hamil sebagai Pelayanan Prenatal dalam Menurunkan Kecemasan Menghadapi Persalinan Pertama. INSAN 8.

Http:// www.anxiety and pregnancy. com. Diakses tanggal 10 April 2012.

Hypnobirthing, Kurangi Sakit Waktu Persalinan.2008. Available from URL: http://www.hypnobirthing.web.id/?p=455. Diakses tanggal 20 April 2012 